\title{
PREVALENCE OF UNINTENTIONAL INJURIES AND RELATED RISK FACTORS AMONG UNIVERSITY STUDENTS IN CANAKKALE CITY, WESTERN TURKEY
}

\author{
Coşkun Bakar', Sibel Cevizci', Duru Gündoğar², Handan Işın Özışık Karaman³ \\ 'Department of Public Health, School of Medicine, Canakkale Onsekiz Mart University, Canakkale, Turkey \\ ${ }^{2}$ Department of Psychiatry, School of Medicine, Suleyman Demirel University, Isparta, Turkey \\ ${ }^{3}$ Department of Neurology, School of Medicine, Canakkale Onsekiz Mart University, Canakkale, Turkey
}

\section{SUMMARY}

Objective: We examined the prevalence of unintentional injuries and associated risk factors among university students in Canakkale city, Turkey.

Methods: A cross-sectional study was conducted in 2007-2008. A total of 4,762 students completed the questionnaire. Risk factors associated with the rate of accidents were assessed by chi-square analysis and effects of these factors on unintentional injuries were described by logistic regression analysis.

Results: The rate of unintentional injuries among university students was $14.9 \%$ during the previous 12 months. The most reported injuries occurred on the road (43.8\%), at home (33.2\%) and outside the home $(26.9 \%)$ such as workplaces, schools or sports venues. The prevalence of unintentional injuries was significantly higher in males than females ( $18.1 \%$ vs. $12.0 \% p<0.05)$. Results of the logistic regression analysis indicated that male gender (OR 1.51), studying in college and vocational school (OR 1.34), perception of very bad (OR 0.49 ) or good economic status (OR 0.49), drinking alcohol (OR 1.52), using illicit substances (OR 1.70), having a diagnosed illness (OR 1.36), or having risk of developing depression (OR 1.54) had significant effects on the risk of unintentional injuries $(p<0.05)$.

Conclusions: This study indicated that male gender, studying in college and vocational schools, illicit substance use, poor economic conditions, having a diagnosed illness and risk of developing depression can be risk factors for unintentional injuries among university students. Public health training programmes giving priority to high-risk groups such as university and high school students may be a valuable tool in reducing unintentional injuries among young people.

Key words: unintentional injuries, risk factors, university students

Address for correspondence: S. Cevizci, Department of Public Health, School of Medicine, Canakkale Onsekiz Mart University, Terzioglu Campus, 17100, Canakkale, Turkey. E-mail: cevizci.sibel@gmail.com

\section{INTRODUCTION}

In the world, $9 \%$ of all deaths occur due to trauma, and the majority of these deaths cause social and economic losses in countries with low and moderate income levels (1-4). According to WHO, in 1990 injuries due to traffic accidents were ninth among the first 10 causes of global disease burden. In 2020, they are expected to be located in third place after ischaemic cardiac disease and unipolar major depression. Unless new and effective programmes are developed, these figures are expected to increase by $65 \%$ in the following 20 years. In order to define factors which increase or decrease injury risk, epidemiological studies, which are based primarily on public health approaches specific for each region, are required (5).

Worldwide, 8 of the 15 leading causes of death for people aged 15 to 29 years are injury related, including traffic injuries, homicide, suicide, etc. (6). Also nearly 1.3 million people die, and 20-50 million are injured or disabled each year. Road crashes are the leading cause of death among young people aged 15-29 years. In the USA, over 37,000 people die, and 2.35 million are injured or disabled in road crashes each year. Nearly 8,000 people are killed in crashes involving drivers aged 16-20 years. Crash death rates among 15-24 years of age have been reported as 10.9 deaths per 100,000 people (7).

According to the Turkish National Disease Burden Study, numbers of deaths due to undesired injury and crashes at the ages 15-29 were 6,332 and 6,485 in the year 2000 and 2010, respectively. The numbers are expected to be 6,434 and 6,242 in 2020 and 2030, respectively. For the same age group, the ratio of undesired injuries was $16.7 \%$ of total disease burden (disability life adjusted years - DALY); the ratio is $11.9 \%$ in men and $5.2 \%$ in women. Traffic accidents are fifth (3.3\%) for men, but 14th for women $(1.5 \%)$ among causes of disease burden. It was reported in the study that being unprepared for accidents and deficiency of psychosocial support are the most important causes of disease burden (8). Moreover, WHO has reported that studies which investigate accident rate and accident types will provide beneficial data to prepare guidelines for safety policies, and effective intervention methods (5).

The purpose of this study was to assess the prevalence of unintentional injuries and related risk factors among university students, who constitute an important risk group for accidents and injuries. 


\section{MATERIALS AND METHODS}

\section{Study Population}

This study was performed in 9 faculties (consisting of 4-year university education), 6 colleges and 7 vocational schools (consisting of 2-year university education) from different campuses of Canakkale Onsekiz Mart University, located in various regions of the city, during the 2007-2008 academic year. The university is located in Canakkale which is a small city in the northwest part of Turkey. During the mentioned period, a total of 19,988 students were receiving education in the undergraduate and college programmes of the university. Females comprised $51.4 \%(10,277)$ and males comprised $48.6 \%(9,711)$ of the students.

The minimum sample size was calculated as 5,034 for the study. A total of 4,762 students were reached (response rate: $94.6 \%)$. Stratified sampling technique was used in determining the distribution of the sample. For this purpose, stratification was carried out with respect to the weights of the faculties and the colleges. School of medicine students, except for the first grade, were excluded from the stratification since they were continuing their courses in another university.

\section{Study Type}

The present study is a cross-sectional type of epidemiological study in which the frequencies of more than one health problem were investigated. Among the aims of the study, the prevalence of headache, the prevalence of having unintentional injuries and the assessment of mental state parameters consisting of depression, anxiety, anger and modes of anger expression were included. Results for the prevalence of unintentional injuries and related risk factors among university students are presented in this article.

\section{Data Collection}

This study was collaborative research conducted by three different disciplines (faculty members from the neurology, psychiatry and public health departments). Prior to the procedure, written permission was obtained from the presidency of the university. Subsequently the faculty and college administrators were contacted to request their support during the data collection step. On dates determined together with the school administrations, surveys were administered to the students in a group setting during a scheduled school day.

The objectives of the study were explained to the students and they were informed about their right to refuse without any negative consequences. Participation in the study was totally voluntary and the questionnaire forms were anonymous. Written informed consent was obtained from the participants. Local research ethical committee approval was not obtained since the local ethical committee was not founded at the time the study was conducted.

The questionnaire form used in the study comprised four parts. In the first part there were questions about the descriptive characteristics of the respondents and the use of tobacco, alcohol and other substances. The second part consisted of questions about headache, the third part consisted of questions about accidents in the past year, and the fourth part consisted of scales concerning mental state i.e., the Beck Depression Inventory (BDI), the Beck
Anxiety Inventory (BAI), and the State-Trait Anger Inventory (STAI).

The pilot application of the questionnaire form was carried out on 30 students from the first grade of the school of medicine. Following the pilot study, the questionnaire form was revised to create the final version.

For the questions concerning tobacco, alcohol, and substance use, the National Burden of Disease and Cost Effectiveness Project Household Survey carried out by the Ministry of Health was used (9).

The questions inquiring about cigarette smoking, alcohol and illicit substance use were closed-ended and the responses were as follows: "No, I never used"; "I tried once; I'm not using currently"; "I used a few times; I'm not using currently"; "I use occasionally"; or "I use regularly".

These options were reorganized in order to perform the logistic regression analysis. In the cigarette and alcohol questions, the "No, I never used" response was coded as "Never used (0)"; "I tried once, I'm not using currently" and "I used a few times, I'm not using currently" responses were coded as "Tried once or a couple of times, not using currently (1)"; and "I use occasionally" and "I use regularly" responses were coded as "Using occasionally or regularly (2)". For substance use "No, I never used" response was coded as "Never used (0)" and the other responses were coded as "Used at least once (1)".

\section{Beck Depression Inventory (BDI)}

BDI was first developed by Beck et al. (1961) and with its 1978 version $(9,10)$ it was adapted to obtain a self- report scale easier for scoring. It consists of 21 items rated 0 to 3 , with a maximum score of 63 and a cut-off score of 17 . The Turkish adaptation of the scale was made by Tegin (1980) and Hisli $(1988,1989)$ (11-13). The Turkish version of BDI is widely used for healthy and clinical populations.

\section{Statistical Analysis}

Data were entered in the Epi-Info version 6 statistical programme by the researchers. After being checked, the data was later transferred to the SPSS 19.0 statistical programme to be analysed. The risk factors affecting prevalence of accidents were investigated by chi-square and logistic regression analysis. In the logistic regression analysis, gender, school, education of mother and father, perception of income status, and BDI score were taken as the independent variables for the prevalence of accidents. Statistical significance was accepted as $\mathrm{p}<0.05$.

\section{RESULTS}

\section{Descriptive Data}

In this study, 4,762 students were investigated of whom $53.1 \%$ were female, $52.6 \%$ were faculty students and $47.4 \%$ were college students. Mean age of the students was $20.4 \pm 2.1$. Regarding mothers and fathers of the students, $78.6 \%$ and $61.9 \%$, respectively, attained an education level of primary school or less. The income of the families was 1,500 USD and below in $76.7 \%$ of 
the subjects. Average BDI score was estimated to be $11.7 \pm 8.1$ and $24.6 \%$ had a BDI score of 17 and above. Of the respondents, $42.6 \%$ were staying in dormitories and $57.4 \%$ were staying at home with friends or with their families. Of the investigated students, $34.9 \%$ have never smoked in their life while $24.8 \%$ smoked regularly every day. Regarding alcohol, those who never drank alcohol constituted $33.8 \%$ of the study population, while $37.9 \%$ drank alcohol occasionally, and 8.1\% drank alcohol regularly. Of the students $93.7 \%$ had never used an illicit substance in their life, $2.9 \%$ tried an illicit substance once, but were not using currently, $1.2 \%$ were using occasionally, and $0.1 \%$ were using regularly.

\section{Univariate Analysis}

We found that the prevalence of unintentional injuries among university students was $14.9 \%$ during the past 12 months. The most commonly reported injuries were road injuries(43.8\%), and injuries occurring at home (33.2\%) and outside home (26.9\%) at places such as schools, workplaces, or sports venues. The prevalence of unintentional injuries was significantly higher in males than in females $(18.1 \%$ vs. $12.0 \% \mathrm{p}<0.001)$. In addition, the rate of unintentional injuries was found to be higher in those who were using tobacco, drinking alcohol, substance use, who had a parent with high education level and in those who perceived their economic situation as very poor $(\mathrm{p}<0.05)$ (Table 1$)$. According to the chi-square analysis having an illness diagnosed by a doctor and seeking professional help, academic programme and risk of developing depression considering BDI score were also found to be related to prevalence of unintentional injuries.

\section{Mutivariate Analysis}

We observed that there was a statistically significant association between some variables and prevalence of unintentional injuries. However, we couldn't say whether there was a causal relation between these variables found to be significant and accident risk. Therefore, it was decided to perform logistic regression analysis. The models were developed using a forward stepwise method and adding the variables in blocks (Table 2). Firstly, we investigated the effect of socio-demographic characteristics on prevalence of unintentional injuries in the first model. We found that the risk of unintentional injuries was 1.5 (95\% CI 1.31-1.81) times higher in males, 1.6 (95\% CI 1.31-1.84) times more likely in the students of college and vocational high schools, $1.3(95 \%$ CI 1.06-1.63) times more likely in the students with mothers' educational level of high school and higher, 0.4 times more likely in those who have moderate (95\% CI $0.22-0.75)$ and good (95\% CI $0.22-0.73)$ perception of economic condition. In addition, it was 0.5 (95\% CI $0.25-0.88)$ times higher in those who have very bad economic status (Table 2).

Secondly, we added the substance use including smoking status, alcohol drinking and illicit substance use into the logistic regression analysis. The OR decreased from 1.5 to $1.3(95 \%$ CI:1.13-1.59) when variables related to substance use were added, however, the significant association between male gender and risk of unintentional injuries did not disappear. We also observed that the risk of unintentional injuries was: 1.4 (95\% CI $1.20-1.70)$ times more likely in the students of college and vocational high schools, 0.4 times more likely in those who have moderate $(95 \%$
CI $0.22-0.75)$ and good (95\% CI $0.22-0.74)$ perception of economic condition, 0.5 (95\% CI $0.24-0.86)$ times higher in those who have very bad economic status perception, 1.7 (95\% CI 1.27-2.23) times higher in those who have used an illicit substance at least once, and 1.6 (95\% CI 1.25-1.95) times more likely in those who drank alcohol occasionally or regularly. However, in this second model, it was found that the association between mothers' educational level and accident risk disappeared (Table 2).

Thirdly, we added variables related to health status into Model 3. In Model 3 of logistic regression analysis, OR increased from 1.3 to $1.5(95 \%$ CI $1.26-1.81)$ when variables related to health status were added. We observed that unintentional injury risk was 1.5 times higher in males, 1.3 (95\% CI 1.12-1.61) times more likely in the students of college and vocational high schools, 0.5 (95\% CI 0.24-0.99) times more likely in those who have very bad economic status perception and also 0.5 (95\% CI 0.25-0.96) times more likely in those who had good economic status perception, 1.7 (95\% CI 1.27-2.27) times higher in those who had used an illicit substance at least once, 1.5 (95\% CI 1.20-1.92) times more likely in those who drank alcohol occasionally or regularly, 1.4 (95\% CI 1.12-1.67) times higher in those who had a diagnosed illness, and 1.5 (95\% CI 1.28-1.86) times higher in those who had risk of developing depression (Table 2).

\section{DISCUSSION}

In the present study, the aim was to evaluate one yearprevalence of unintentional injuries and associated risk factors among university students in Canakkale city in Turkey. To our knowledge, only a few studies have estimated prevalence of unintentional injuries for university students. In addition, to date, rates for Turkish university students have been unknown. The present cross-sectional study revealed that the prevalence of unintentional injuries among university students was 14.9\% during the past 12 months. The prevalence of unintentional injuries was significantly higher in males than in females (18.1\% vs. $12.0 \%$ $\mathrm{p}<0.001)$. In a study from Germany, 252 university students $(\mathrm{N}=2,855)$ reported that they had an accident at least once in their lifetime (14). Unintentional injury is the leading cause of death among adolescents 10-19 years of age. Fatal injury rates of males are twice as high as those of females (6). In another study from Finland, 117 university students $(\mathrm{N}=617)$ reported a combined total of 281 accidents and 323 separate injuries. Almost half of all accidents had been sustained during sports activities and 14\% in traffic. Alcohol was involved in $10.1 \%$ of the accidents (15). In a register-based study from Egypt, injury-related mortalities comprised a total of 19,731 deaths between 2000 and 2010. Incidence ranged between 38.3/100,000 and 51.5/100,000. Road traffic accident was the leading cause of death (16). In our study, we revealed that the rate of accidents was found to be higher in those who were using tobacco and other substances, drinking alcohol, who had a parent with high education level and in those who perceived their economic situation as very poor.

The risk of motor vehicle crashes is higher among 16 to 19 year-olds than among any other age group (17). According to the WHO and European Region reports, road traffic injuries are a major public health problem. About 127,000 people are killed and about 2.4 million injured every year. Road traffic injuries are the 
Table 1. The rate of accidents (unintentional injuries) and related risk factors among university students during the last 12 months, Canakkale, 2008

\begin{tabular}{|c|c|c|c|c|c|}
\hline \multirow{3}{*}{$\begin{array}{l}\text { Variables } \\
\text { Socio-demographic characteristics } \\
\text { Gender }\end{array}$} & \multicolumn{5}{|c|}{ Accident status } \\
\hline & \multicolumn{2}{|c|}{ Yes } & \multicolumn{2}{|c|}{ No } & \multirow{2}{*}{$\mathrm{p}$} \\
\hline & $\mathrm{n}$ & $\%$ & $\mathrm{n}$ & $\%$ & \\
\hline Female & 304 & 12 & 2,227 & 88 & \multirow{2}{*}{$<0.001^{*}$} \\
\hline Male & 404 & 18.1 & 1,827 & 81.9 & \\
\hline \multicolumn{6}{|l|}{ Age } \\
\hline $17-20$ & 412 & 14.9 & 2,351 & 85.1 & \multirow{3}{*}{0.822} \\
\hline $21-24$ & 277 & 14.7 & 1,609 & 85.3 & \\
\hline $25+$ & 19 & 16.8 & 94 & 83.2 & \\
\hline \multicolumn{6}{|l|}{ Academic programme } \\
\hline Faculty & 309 & 12.3 & 2,196 & 87.7 & \multirow{2}{*}{$<0.001$} \\
\hline College and vocational high school & 399 & 17.7 & 1,858 & 82.3 & \\
\hline \multicolumn{6}{|l|}{ Education of mother } \\
\hline Primary school and lower & 527 & 14.1 & 3,217 & 85.9 & \multirow{2}{*}{$0.003^{*}$} \\
\hline High school and higher & 181 & 17.8 & 837 & 82.2 & \\
\hline \multicolumn{6}{|l|}{ Education of father } \\
\hline Primary school and lower & 413 & 14 & 2,535 & 86 & \multirow{2}{*}{$0.034^{*}$} \\
\hline High school and higher & 295 & 16.3 & 1,519 & 83.7 & \\
\hline \multicolumn{6}{|l|}{ Perception of economic condition } \\
\hline Very bad & 17 & 31.5 & 37 & 68.5 & \multirow{5}{*}{$0.008^{*}$} \\
\hline Bad & 79 & 16.2 & 410 & 83.8 & \\
\hline Moderate & 441 & 14.3 & 2,651 & 85.7 & \\
\hline Good & 160 & 15.1 & 901 & 84.9 & \\
\hline Very good & 10 & 18.5 & 44 & 81.5 & \\
\hline \multicolumn{6}{|l|}{ Marriage status } \\
\hline Single & 699 & 14.8 & 4,010 & 85.2 & \multirow{2}{*}{0.388} \\
\hline Married/Divorced & 9 & 17.3 & 44 & 82.7 & \\
\hline \multicolumn{6}{|l|}{ Smoking status } \\
\hline Never used & 188 & 11.3 & 1,473 & 88.7 & \multirow{2}{*}{$<0.001^{*}$} \\
\hline Tried at least once & 520 & 16.8 & 2,581 & 83.2 & \\
\hline \multicolumn{6}{|l|}{ Illicit substance use } \\
\hline Never used & 625 & 14 & 3,837 & 86 & \multirow{2}{*}{$<0.001^{*}$} \\
\hline Tried at least once & 83 & 27.7 & 217 & 72.3 & \\
\hline \multicolumn{6}{|l|}{ Alcohol drinking } \\
\hline Never used & 162 & 10.1 & 1,446 & 89.9 & \multirow{2}{*}{$<0.001^{*}$} \\
\hline Tried at least once & 546 & 17.3 & 2,608 & 82.7 & \\
\hline \multicolumn{6}{|l|}{ Diagnosed illness } \\
\hline Yes & 182 & 17.3 & 868 & 82.7 & $0010 *$ \\
\hline No & 526 & 14.2 & 3,179 & 85.8 & 0.012 \\
\hline Risk of developing depression (BDI scc & & & & & \\
\hline Yes & 217 & 19.7 & 886 & 80.3 & $<0001 *$ \\
\hline No & 437 & 12.9 & 2,939 & 87.1 & -0.001 \\
\hline
\end{tabular}

p: Chi-square test; * $p<0.05$

leading cause of death among young people aged 15-29 years (18, 19). In our study, we have also shown that the most reported accidents happened on the road (43.8\%) among university students. In a study performed in 25 European and North American coun- tries, there was an association between risk behaviours (smoking, alcohol drinking, etc.) and adolescent injury (20). In Turkey, the number of deaths caused by unintentional accidents and injuries in males reached 5th place among all deaths. Males are more at 
Table 2. Investigation of the factors affecting the accidents (unintentional injuries) among university students with logistic regression analysis, Canakkale, 2008

\begin{tabular}{|c|c|c|c|}
\hline Risk factors & Model 1 & Model 2 & Model 3 \\
\hline Gender & OR $(95 \% \mathrm{Cl})$ & OR $(95 \% \mathrm{Cl})$ & OR $(95 \% \mathrm{Cl})$ \\
\hline Female $^{\#}$ & 1 & 1 & 1 \\
\hline Male & $1.54(1.31-1.81)^{\mathrm{c}}$ & $1.34(1.13-1.59)^{b}$ & $1.51(1.26-1.81)^{\mathrm{c}}$ \\
\hline \multicolumn{4}{|l|}{ Age } \\
\hline $17-20^{\#}$ & 1 & 1 & 1 \\
\hline $21-24$ & $1.05(0.89-1.25)^{\text {a }}$ & $0.97(0.81-1.16)^{\text {a }}$ & $0.97(0.81-1.17)^{\mathrm{a}}$ \\
\hline $25+$ & $1.21(0.73-2.02)^{\text {a }}$ & $1.11(0.66-1.87)^{a}$ & $1.07(0.62-1.85)^{\mathrm{a}}$ \\
\hline \multicolumn{4}{|l|}{ Academic programme } \\
\hline Faculty\# & 1 & 1 & 1 \\
\hline College and vocational high school & $1.55(1.31-1.84)^{c}$ & $1.43(1.20-1.70)^{c}$ & $1.34(1.12-1.61)^{b}$ \\
\hline \multicolumn{4}{|l|}{ Education of mother } \\
\hline Primary school and lower & 1 & 1 & 1 \\
\hline High school and higher & $1.31(1.06-1.63)^{b}$ & $1.19(0.95-1.48)^{a}$ & $1.20(0.95-1.50)^{\mathrm{a}}$ \\
\hline \multicolumn{4}{|l|}{ Education of father } \\
\hline Primary school and lower" & 1 & 1 & 1 \\
\hline High school and higher & $1.16(0.96-1.40)^{\text {a }}$ & $1.12(0.93-1.35)^{\text {a }}$ & $1.13(0.92-1.37)^{a}$ \\
\hline \multicolumn{4}{|l|}{ Perception of economic condition } \\
\hline Very bad & $0.47(0.25-0.88)^{b}$ & $0.45(0.24-0.86)^{b}$ & $0.49(0.24-0.99)^{b}$ \\
\hline Bad & $0.45(0.18-1.12)^{\text {a }}$ & $0.45(0.18-1.12)^{\text {a }}$ & $0.62(0.24-1.64)^{a}$ \\
\hline Moderate & $0.41(0.22-0.75)^{b}$ & $0.41(0.22-0.75)^{b}$ & $0.51(0.26-1.01)^{a}$ \\
\hline Good & $0.40(0.22-0.73)^{b}$ & $0.41(0.22-0.74)^{b}$ & $0.49(0.25-0.96)^{b}$ \\
\hline Very good" & 1 & 1 & 1 \\
\hline \multicolumn{4}{|l|}{ Smoking status } \\
\hline Never used ${ }^{\#}$ & - & 1 & 1 \\
\hline Tried once or a couple times, not using regularly & - & $1.17(0.94-1.47)^{\text {a }}$ & $1.13(0.90-1.43)^{\mathrm{a}}$ \\
\hline Using occasionally or regularly & - & $1.18(0.94-1.47)^{\mathrm{a}}$ & $1.08(0.86-1.36)^{\mathrm{a}}$ \\
\hline \multicolumn{4}{|l|}{ Illicit substance use } \\
\hline Never used\# & - & 1 & 1 \\
\hline Used at least once & - & $1.68(1.27-2.23)^{c}$ & $1.70(1.27-2.27)^{\mathrm{c}}$ \\
\hline \multicolumn{4}{|l|}{ Alcohol drinking } \\
\hline Never used ${ }^{\#}$ & - & 1 & 1 \\
\hline Tried once or a couple times, not using regularly & - & $1.28(0.99-1.65)^{\text {a }}$ & $1.29(0.99-1.69)^{\mathrm{a}}$ \\
\hline Using occasionally or regularly & - & $1.56(1.25-1.95)^{\mathrm{c}}$ & $1.52(1.20-1.92)^{b}$ \\
\hline \multicolumn{4}{|l|}{ Diagnosed illness } \\
\hline Yes & - & - & $1.36(1.12-1.67)^{b}$ \\
\hline $\mathrm{No}^{\#}$ & - & - & 1 \\
\hline \multicolumn{4}{|l|}{ Risk of developing depression (BDI score) } \\
\hline Yes & - & - & $1.54(1.28-1.86)^{c}$ \\
\hline $\mathrm{No}^{\#}$ & - & - & 1 \\
\hline
\end{tabular}

${ }^{a} p>0.05,{ }^{b} p<0.05,{ }^{c} p<0.001$

\# Item was accepted as a reference value

In Logistic regression analysis, Model 1 included socio-demographic characteristics; Model 2: socio-demographic characteristics + substance use; Model 3: socio-demographic characteristics + substance use + health status.

risk than females (6). The present study revealed that the male gender (OR 1.5), being a student in college and vocational high school (OR 1.3), perceiving poor and good economic status (OR
0.5), using an illicit substance at least once (OR 1.7), drinking alcohol occasionally or regularly (OR 1.5), having a diagnosed illness (OR 1.4), and being at risk of developing depression (OR 
1.5) increased the prevalence of unintentional injuries among university students.

According to reports, socio-economic status, age, and gender are found to be the risk factors most related to road accidents (18, 21). More than $90 \%$ of deaths caused by road traffic injuries occur in low- and middle-income countries. Children and young people under the age of 25 years account for over $30 \%$ of those killed and injured in road traffic crashes. Young males under the age of 25 years are almost 3 times as likely to be killed in a car crash as young females (18). Our findings are consistent with these reports.

During the school education period, injuries are reported in first place among health risks. As observed in every age group, accidents may cause various outcomes from functionality losses of various levels to death during the education period (22). In a training workshop it was found that children were highly compliant with safety measures like wearing helmets and being aware of traffic lights. Of students, $25.1 \%$ declared they had traffic accidents, $23.6 \%$ had house accidents, and $11.2 \%$ had school accidents previously (23). In a study conducted about unintentional injury prevalence among university students in Germany, 252 $(8.8 \%)$ out of 2,855 students reported that they had experienced an accident at least once. Approximately $60 \%$ of all accidents occurred during work-related sports activities, and one fourth had accidents on the road to or from university (14). In a study performed on 618 students by Rahman et al., 6.8\% of them reported that they had experienced a traffic accident. Although there was no significant difference between students in terms of gender, a significant relationship was defined between variables of having no licence, no driving lessons and car accidents (24). In our study group, students were found to have traffic accidents at a rate of $43.8 \%$, home accidents at $33.2 \%$, and accidents outside of house at $26.9 \%$ (in work environment, school, during sports activities). In a study performed on 265 university students aged between 18 and 24 years in Iran-Kerman, the rate of females involved in traffic accidents was lower than that of males (25). In a study performed in Virginia-USA, death rate was defined as 4.3 per 100,000 students. It was defined that $38.9 \%$ of the deaths which occurred in traffic were due to alcohol, and death rate in alcohol-related motor accidents was 1.7 per 100,000 students (26). According to single variable analysis results of our study, smoking and alcohol use was statistically correlated with accident prevalence among university students $(\mathrm{p}<0.05)$. Also factors affecting accident were grouped and investigated in the logistic regression analysis, and as a result it was defined that alcohol and illegal substance use increased unintentional injury risk (OR 1.52, 95\% CI 1.20-1.92) and (OR $1.70,95 \%$ CI 1.27-2.27), respectively, $(\mathrm{p}<0.05)$.

In our study, prevalence of having an accident with respect to gender was higher in men than women. This difference was markedly prominent in individuals below the age of 25 years, as it has been shown in many studies (27-31). According to the literature, there are also other factors affecting accident incidence and increasing accident risk among adolescents. These factors may include sleep disorders (32), and using mobile phones especially during driving (33). Inadequate sleep may affect mood and behaviour in children and adolescents, so accident and injury risks are increased (32). In our study, it was defined that risk of accident increases among university students who had high potential to develop depression according to BDI score (OR 1.54, 95\% CI $1.28-1.86)(\mathrm{p}<0.05)$. During childhood, increased independence, peer pressure, and changes in physical activities are the most important factors which increased accident occurrence (23). It is believed that increased accidents occurrence especially among males in the 15-29 years age group is increased by risk factors like risk-taking behaviour during the period, fast driving in traffic, and drink-driving (21). It was shown in another study performed among university students in Israel, that females were more compliant and attentive to traffic rules than males (34). Young individuals aged 15-25 years struggle to present their own identities by expressing their own decisions and values. They are also faced with some risks during that sensitive period. However, such risky behaviour, which they may not be conscious of, may have negative outcomes. Especially traffic accidents caused by drunk driving are one of the most fatal outcomes $(35,36)$. In another Turkish study, male students were found to be engaged in risky behaviour more frequently than females. In addition, gender, place of residence, relationship with parents, and socialization with friends have profound effects on risk behaviours (37).

Risk factors like alcohol and drug use, and working in different part-time jobs can be effective in accidents $(38,39)$. Training programmes for small age groups in schools may be beneficial in protecting young individuals from these risk factors, prevention of accidents, and development of protective behaviour against occupational injuries. Determination of risky behaviour in crosssectional studies of these target groups, which have not developed accident risk awareness yet, and improvement of accident risk perception and awareness would be possible with continuous and effective protective programmes in schools $(24,38)$.

Currently, the increasing numbers of traffic accidents are an important public health problem. Worldwide, millions of adolescents die or are injured due to traffic accidents, annually. Moreover, intervention programmes, which may prevent injuries related to traffic accidents in adolescents especially in developed countries, are insufficient (40). Studies, which investigate the causative risk factors for accidents, are required in order to identify preventive measures (14). The first stage, in which subjects have a high risk for being involved in an accident, is the young age period. Risky behaviour and incomplete development of risk awareness are not only important, but also preventable risk factors in young people. Therefore, definition and taking precautions to decrease or to eradicate risky behaviour among young adults are inevitable preventive chances from the public health point of view $(41,42)$.

It is expected that data obtained from our study will be used in definition of risky conditions especially in young age groups in our country as well as in preparation of interventional programmes targeted at them.

\section{Strengths and Limitations}

To our knowledge, this is the first comprehensive study of unintentional injuries among university students from Turkey that also investigates associated factors. Our study has some limitations that need to be considered in evaluating the data. First, our data were obtained from questionnaires filled by students themselves. Because the register systems related to accidents and injuries are not so good, we couldn't get hospital or other formal register data. In addition, WHO reported that in many countries it is extremely difficult to obtain reliable data on the number of road traffic deaths and injuries. Underreporting of deaths and injuries resulting from 
road traffic crashes is known to be widespread, and may be more common among children, particularly when they incur moderate injuries (21). Second, although we used a prospectively recruited sample, it was not population-based. Finally, smoking status, alcohol consumption, substance use, and also unintentional accidents were determined by self-report without biometric verification and registry reports.

\section{CONCLUSIONS}

Despite these limitations, our findings have important implications for understanding the role of socio-demographic conditions, substance use and risk of developing depression on unintentional injuries among university students.

In our study, we investigated unintentional injuries among university students. The present study revealed that the male gender, studying in college and vocational schools, perception of very poor economic condition, illicit substance use and high risk of developing depression were among the risk factors associated with the unintentional injuries in university students. Implementation of training programmes giving priority to high-risk groups such as university and high school students is expected to reduce the unintentional injuries in young age groups.

We have provided one of the first estimates of the prevalence of unintentional injuries and risk factors associated with accidents among university students. We suggest that children and young adults should be monitored and educated to prevent injuries/ accidents in schools, work-environments, at home, outside the home, and during sports activities.

\section{Conflict of Interests}

None declared

This study was presented at the APHA 140th Annual Meeting in San Francisco, October 27-31 2012, USA.

\section{REFERENCES}

1. Yiengprugsawan V, Stephan K, McClure R, Kelly M, Seubsman S, Bain C, et al.; Thai Cohort Study Team. Risk factors for injury in a national cohort of 87,134 Thai adults. Public Health. 2012 Jan;126(1):33-9.

2. Krug EG, Sharma GK, Lozano R. The global burden of injuries. Am J Public Health. 2000 Apr;90(4):523-6.

3. Nakahara S, Ichikawa M. Injuries are growing public health concern in low- and middle-income countries (LMICs). J Trauma. 2006 Sep;61(3):768.

4. Nantulya VM, Reich MR. The neglected epidemic: road traffic injuries in developing countries. BMJ. 2002 May 11;324(7346):1139-41.

5. Peden $\mathrm{M}$, et al., editors. World report on road traffic injury prevention: summary. Geneva: WHO; 2004.

6. Sleet DA, Pogostin CL, Bryn CS, Haverkos L, Spavone S, Levin R, et al. Child and adolescent injury prevention: a public health perspective. In: Liller KD, editor. Injury prevention for children and adolescents: research, practice, and advocacy. 2nd ed. Washington: American Public Health Association; 2012. p. VII-X.

7. Turkish Statistical Institute. Summary statistics on transportation 2011. Anakara: Turkish Statistical Institute; 2012.

8. Ministry of Health, Refik Saydam Hygiene Center Presidency, School of Public Health; Başkent University. Burden of disease: final report. National Burden of Disease and Cost Effectiveness Project. Anakara: Ministry of Health, Refik Saydam Hygiene Center Presidency, School of Public Health; 2004

9. Ministry of Health, Refik Saydam Hygiene Center Presidency, School of Public Health; Başkent University. Household survey: interim report.
National Burden of Disease and Cost Effectiveness Project. Anakara: Ministry of Health, Refik Saydam Hygiene Center Presidency, School of Public Health; 2004.

10. Beck AT, Rush AJ, Shaw BF, Emery G. Cognitive therapy of depression. The Guilford clinical psychology and psychotherapy series. New York: Guilford Press; 1979.

11. Tegin B. Cognitive disorders in depression: an evaluation according to the Beck model [dissertation]. Ankara: Hacettepe University; 1980. (In Turkish.)

12. Hisli N. A study on the validity of Beck Depression Inventory. Turk J Psychol. 1988;6(22):118-23. (In Turkish.)

13. Hisli N. Validity and reliability of the Beck Depression Inventory in university students. Turk J Psychol. 1989;7(23):3-13. (In Turkish.)

14. Faller G, Mikolajczyk RT, Akmatov MK, Meier S, Krämer A. Accidents in the context of study among university students - A multicentre crosssectional study in North Rhine-Westphalia, Germany. Accid Anal Prev. 2010 Mar;42(2):487-91.

15. Sane J, Ylipaavalniemi P, Turtola L, Niemi T, Laaka V. Traumatic injuries among university students in Finland. J Am Coll Health. 1997 Jul;46(1):21-4.

16. Wahab MM. Incidence and patterns of injury-related mortality: a registerbased follow-up study in Alexandria, Egypt (2000-2010). J Egypt Public Health Assoc. 2012 Apr;87(1-2):8-15.

17. Centers for Disease Control and Prevention. Injury prevention \& control: motor vehicle safety. Teen drivers: fact sheet [Internet]. Atlanta: CDC 2012 [cited 2014 Aug 28]. Available from: http://www.cdc.gov/motorvehiclesafety/teen drivers/teendrivers factsheet.html.

18. World Health Organization. Media centre. Road traffic injuries. Fact sheet no. 358 [Internet]. Geneva: WHO; 2013 [cited 2014 Aug 28]. Available from: http://www.who.int/mediacentre/factsheets/fs358/en/index.html.

19. Racioppi F, Eriksson L, Tingvall C, Villaveces A. Preventing road traffic injury: a public health perspective for Europe. Copenhagen: WHO; 2004.

20. de Looze M, Pickett W, Raaijmakers Q, Kuntsche E, Hublet A, Gabhainn $\mathrm{SN}$, et al. Early risk behaviors and adolescent injury in 25 European and North American countries a cross-national consistent relationship. J Early Adolesc. 2012;32(1):104-125.

21. Toroyan T, Peden M, editors. Youth and road safety. Geneva: WHO; 2007.

22. Youth with disabilities: risk factors for injury: data monograph [Internet]. Washington State Department of Health; 2009 [cited 2014 Aug 28]. Available from: http://www.doh.wa.gov/Portals/1/Documents/Pubs/160023_YouthWithDisabilitiesRiskFactorsForInjury.pdf.

23. Hall-Long BA, Schell K, Corrigan V. Youth safety education and injury prevention program. Pediatr Nurs. 2001 Mar-Apr;27(2):141-6.

24. Abdul Rahman H, Mohd Zulkifli NA, Subramaniam K, Law TH. Car occupants accidents and injuries among adolescents in a state in Malaysia. Proceedings of the Eastern Asia Society for Transportation Studies. 2005;5:1867-74.

25. Mohammadi G. Prevalence of seat belt and mobile phone use and road accident injuries amongst college students in Kerman, Iran. Chin J Traumatol. 2011 Jun 1;14(3):165-9

26. Turner J, Bauerle J, Keller A. Alcohol-related vehicular death rates for college students in the Commonwealth of Virginia. J Am Coll Health. 2011;59(4):323-6.

27. Social Issues Research Centre. Sex differences in driving and insurance risk: an analysis of the social and psychological differences between men and women that are relevant to their driving behaviour. Oxford: Social Issues Research Centre; 2004.

28. Abdel-Aty MA, Abdelwahab HT. Exploring the relationship between alcohol and the driver characteristics in motor vehicle accidents. Accid Anal Prev. 2000 Jul;32(4):473-82.

29. Waller PF, Elliott MR, Shope JT, Raghunathan TE, Little RJA. Changes in young adult offense and crash patterns over time. Accid Anal Prev. 2001 Jan;33(1):117-28.

30. Waylen A, McKenna F; AA Foundation for Road Safety Research. Cradle attitudes - grave consequences: the development of gender differences in risky attitudes and behaviour in road use. University of Reading; 2002.

31. Lancaster R, Ward R. The Contribution of individual factors to driving behaviour: implications for managing work-related road safety. Norwich: Her Majesty's Stationery Office; 2002.

32. Marhefka JK. Sleep deprivation: consequences for students. J Psychosoc Nurs Ment Health Serv. 2011 Sep;49(9):20-5

33. Stavrinos D, Byington KW, Schwebel DC. Distracted walking: cell phones increase injury risk for college pedestrians. J Safety Res. 2011 Apr;42(2):101-7. 
34. Yagil D. Gender and age-related differences in attitudes toward traffic laws and traffic violations. Transp Res Pt F-Traffic Psychol Behav. 1998;1(2):123-35.

35. Miller PH. Theories of adolescent development. In: Worell J, Danner F, editors. The adolescent as decision-maker: applications to development and education. San Diego: Academic Press; 1989. p. 13-46.

36. Jeftha A. The construction of masculinity and risk-taking behaviour among adolescent boys in seven schools in the Western Cape [dissertation]. Cape Town: University of the Western Cape; 2006.

37. Ozcebe H, Uner S, Tezcan S, Erbaydar NP, Teletar G. Risky behaviors of university students: a cross-sectional study. Turk J Public Health. 2012;10(1):1-12

38. Kıran S, Konuk N, Atik L, Saltık B, Şahin Z, Ayoğlu FN. Alcohol consumption in work-related occupational injuries. J Depend. 2006;7(3):1238. (In Turkish.)
39. Bekibele CO, Fawole OI, Bamgboye AE, Adekunle LV, Ajav R, Baiyeroju AM. Risk factors for road traffic accidents among drivers of public institutions in Ibadan, Nigeria. Afr J Health Sci. 2007;14(3-4):137-42.

40. Zhang C, Hong Y, Liu X, Li Y, Yang J. Evaluation of a school-based intervention to reduce traffic-related injuries among adolescents in Beijing. World Health Popul. 2010;12(2):34-42.

41. Hingson RW, Zha W, Weitzman ER. Magnitude of and trends in alcoholrelated mortality and morbidity among U.S. college students ages 18-24, 1998-2005. J Stud Alcohol Drugs Suppl. 2009 Jul;(16):12-20.

42. Ferreira AI, Martínez LF, Guisande MA. Risky behavior, personality traits and road accidents among university students. Eur J Educ Psychol. 2009;2(2):79-98.

Received November 1, 2013 Accepted in revised form March 19, 2014 